\title{
Prognostic significance of sodium-potassium ATPase regulator, FXYD3, in human hepatocellular carcinoma
}

\author{
LI-JUAN WANG $^{1,2^{*}}$, QI-JIONG LI ${ }^{1,2^{*}}$, YONG LE $^{1,2}$, HAN-YUE OUYANG $^{1,2}$, \\ MIN-KE HE ${ }^{1,2}$, ZI-SHAN YU ${ }^{1,2}$, YONG-FA ZHANG ${ }^{1,2}$ and MING SHI ${ }^{1,2}$ \\ ${ }^{1}$ State Key Laboratory of Oncology in South China, Collaborative Innovation Center for Cancer Medicine; \\ ${ }^{2}$ Department of Hepatobiliary Oncology, Sun Yat-sen University Cancer Center, Guangzhou, Guangdong 510060, P.R. China
}

Received March 23, 2017; Accepted November 7, 2017

DOI: $10.3892 / \mathrm{ol} .2017 .7688$

\begin{abstract}
The clinical significance of the sodium-potassium ATPase regulator FXYD domain-containing ion transport regulator 3 (FXYD3) has been demonstrated in a number of types of cancer. However, the role of this protein in human hepatocellular carcinoma (HCC) remains to be elucidated. In the present study, 217 HCC tissue samples were analyzed to evaluate the expression and prognostic significance of FXYD3 in HCC. Reverse transcription-quantitative polymerase chain reaction was used to analyze the mRNA expression of FXYD3 in 80 primary HCC specimens and paired non-cancerous liver tissue samples, while western blotting was used to analyze the protein expression level of FXYD3 in another 24 pairs. These analyses demonstrated that the expression level of FXYD3 was significantly increasedb at the mRNA and protein levels in HCC tumor tissues compared with adjacent non-cancerous tissues. Immunohistochemical analysis of 137 paraffin-embedded HCC tissue samples indicated that the expression of FXYD3 was associated with HCC clinicopathological characteristics. Kaplan-Meier analysis demonstrated that patients with high FXYD3 protein expression $(n=60)$ experienced significantly poorer overall survival time compared with patients with low FXYD3 protein expression $(\mathrm{n}=77)(\mathrm{P}<0.001)$. Multivariate analysis demonstrated that FYXD3 protein expression level (hazard ratio, 2.137; 95\% confidence interval, 1.224-3.732; $\mathrm{P}=0.008$ ) was an independent prognostic factor in patients with HCC. Overall, the results indicated that FXYD3 expression levels were higher in HCC tumor tissues than in adjacent non-cancerous tissues, and that the FXYD3 protein may serve as a prognostic marker for HCC.
\end{abstract}

Correspondence to: Professor Ming Shi, Department of Hepatobiliary Oncology, Sun Yat-sen University Cancer Center, 651 East Dongfeng Road, Guangzhou, Guangdong 510060, P.R. China

E-mail: shiming@sysu.edu.cn

${ }^{*}$ Contributed equally

Key words: FXYD domain-containing ion transport regulator 3, human hepatocellular carcinoma, prognosis, overall survival, sodium-potassium ATPase

\section{Introduction}

Hepatocellular carcinoma (HCC) is the 6th most common type of primary malignant neoplasm and the third leading cause of cancer-associated mortality worldwide. The morbidity and mortality rates of the disease increase annually (1-3). HCC forms heterogeneous tumors and its development is driven by numerous factors. Chronic hepatitis B virus (HBV) infection and $\mathrm{HBV}$-associated cirrhosis account for the majority of cases of HCC, which constitutes $70-90 \%$ of liver cancer cases according to histological examination (4). The efficacies of existing key HCC therapies, including hepatectomy, percutaneous ethanol injection, radio frequency ablation and liver transplantation, have improved in recent years. However, the disease often progresses or recurs despite appropriate treatment regimes, and the overall survival (OS) of HCC patients remains poor (5). Therefore, novel molecular markers that contribute to the development of effective treatment strategies and the improved prognosis of patients with $\mathrm{HCC}$ are urgently required.

FXYD domain-containing ion transport regulator 3 (FXYD3), also known as mammary tumor 8, belongs to the FXYD protein family and is localized in the cell membrane and cytoplasm. It has been reported that FXYD3 acts as a regulator of sodium-potassium $\left(\mathrm{Na}^{+}-\mathrm{K}^{+}\right)$ATPase $(6,7)$. One study demonstrated that this integral cell membrane protein was differentially expressed between tumor cells and normal cells, regulated cell proliferation, cell apoptosis and tumor metastasis, influenced the cell cycle, and participated in tumor angiogenesis and progression (8). However, the association between the expression of FXYD3 and tumor occurrence and development remains poorly understood. FXYD3 is expressed in numerous healthy tissues, including the uterus, stomach, colon and skin $(9,10)$. However, FXYD3 expression has also been identified in various types of cancer, including breast cancer $(7)$, prostate cancer $(11,12)$, colorectal cancer (CRC) (13), pancreatic cancer (14-16), esophageal squamous carcinoma (ESCC) $(17)$, lung cancer $(18,19)$ and glioma $(20)$. Furthermore, FXYD3 was demonstrated to be associated with the clinical prognoses of these types of cancer. To the best of our knowledge, the association between FXYD3 expression and HCC prognosis has not been previously evaluated. In the present study, the expression of FXYD3 in HCC tissues was investigated using reverse transcription-quantitative 
polymerase chain reaction (RT-qPCR), western blotting and immunohistochemical (IHC) staining analyses to determine the prognostic value of FXYD3 for patients with HCC.

\section{Materials and methods}

Study population. The present study was approved by the Research Ethics Committee of the Sun Yat-sen University Cancer Center (Guangzhou, China). All patients provided informed consent for study participation prior to undergoing tumor resection. Tissue samples were obtained from 217 patients diagnosed with HCC who had undergone curative resection at the Sun Yat-Sen University Cancer Center between August 2002 and November 2011. Among them, 193 were males and 24 were females, with age ranging from 20-75 years (median, 49 years). A total of 137 paraffin-embedded primary HCC tumor samples were selected (collected between January 2002 and June 2008). Furthermore, 80 pairs of HCC tissues and adjacent non-cancerous liver tissues were also selected from the Sun Yat-sen University Cancer Center specimen repository (originally collected between January 2009 and November 2011). A total of 6 paraffin-embedded breast cancer tissue samples from the Sun Yat-sen University Cancer Center specimen repository were also used in the present study as a positive control.

The following inclusion criteria were applied to the present study: Histologically verified primary HCC, no previous adjuvant chemotherapy, no diagnosis of distant metastases prior to surgery and access to complete follow-up data. Patient tissues were excluded from the study when there was evidence of Child-Pugh class B or C liver disease. Postoperative follow-up included regular recurrence and metastasis surveillance testing by measuring patient serum $\alpha$-fetoprotein levels, abdominal ultrasonography, chest radiography, computed tomography, hepatic angiography and biopsies at 2-4-month intervals. Patients with confirmed disease recurrence received further treatment, including a second surgical resection. The median follow-up time was 43.9 months (range, 1-131 months). A total of 99 mortalities occurred during the follow-up period (45.6\%) and 118 patients (54.4\%) survived. OS was defined as the time from the date of surgery to the date of mortality from any cause, including HCC. Disease-free survival was defined as the time from the date of surgery to the date of regional relapse or distant metastasis, and was determined among the remaining patients on the date of their last follow-up appointment.

$R N A$ extraction and RT-qPCR. Total RNA was extracted from 80 pairs of HCC tissues and matched non-cancerous liver tissues, using TRIzol solution (Invitrogen; Thermo Fisher Scientific, Inc., Waltham, MA, USA) according to the manufacturer's instructions. RNA concentrations were determined using a NanoDrop 2000 Spectrophotometer (Thermo Fisher Scientific, Inc.). RNA with an absorbance ratio from 1.8 to 2.0 at 260 and $280 \mathrm{~nm}$ was considered as pure. Each cDNA sequence was synthesized from $2 \mu \mathrm{g}$ total RNA using a RevertAid First Strand cDNA Synthesis kit (Toyobo Life Science, Osaka, Japan). The resulting cDNA was processed by RT-qPCR to determine the relative FXYD3 mRNA expression levels. GAPDH served as an internal control. RT-qPCR was performed in triplicate at a final volume of $10 \mu \mathrm{l}$, consisting of $5 \mu 12$ X SYBR Green master mix (Toyobo Life Science), $0.4 \mu 1$
$20 \mathrm{mmol} / \mathrm{l}$ forward primer, $0.4 \mu \mathrm{l}$ reverse primer, $0.75 \mu \mathrm{l}$ sample cDNA and $3.45 \mu 1$ RNase-free water. The reaction mixture was preheated to $95^{\circ} \mathrm{C}$ for $10 \mathrm{~min}$, followed by 45 cycles of $95^{\circ} \mathrm{C}$ for $30 \mathrm{sec}$ and $60^{\circ} \mathrm{C}$ for $60 \mathrm{sec}$. The following primers were used for RT-qPCR: FXYD3 forward, 5'-GGACGCCAATGA CCTAGAAG-3' and reverse, 5'-GGGTGATGAGAGGTGG AGTC-3'; and GAPDH forward, 5'-GGAGCGAGATCCCTC CAAAAT-3' and reverse, 5'-GGCTGTTGTCATACTTCT CATGG-3'. The data were analyzed using the quantification cycle $\left(2^{-\Delta \Delta C q}\right)$ method (21) and the results were averaged and expressed in relative expression units after normalization.

Protein extraction and western blotting. Western blotting was performed to analyze the FXYD3 protein expression levels in the clinical specimens from patients with HCC and the matched control tissues. Total protein was extracted from the fresh-frozen tissue samples using radioimmunoprecipitation assay lysis buffer (Beyotime Institute for Biotechnology, Haimen, China) according to the manufacturer's instructions. Protein concentrations were determined using a Bicinchoninic Acid medProtein Assay kit (Thermo Fisher Scientific, Inc.). A total of $30 \mu \mathrm{g}$ protein per sample was separated by $12 \%$ SDS-PAGE and electro-transferred onto polyvinylidene fluoride membranes (Sigma-Aldrich; Merck KGaA, Darmstadt, Germany). The membranes were blocked in 5\% skim milk in Tris-buffered saline-Tween for $60 \mathrm{~min}$ at room temperature. Subsequently, the membranes were incubated overnight at $4^{\circ} \mathrm{C}$ with a rabbit anti-FXYD3 monoclonal antibody (cat. no. ab205534; dilution 1:1,000; Abcam, Cambridge, UK) (22) and GAPDH (cat. no. 10494-1-AP; dilution 1:5,000; ProteinTech Group, Inc., Chicago, IL, USA). Subsequently, the membranes were incubated with appropriate horseradish peroxidase (HRP)-conjugated anti-rabbit IgG (cat. no. 7074; dilution 1:2,000; Cell Signaling Technology, Inc., Danvers, MA, USA) for $60 \mathrm{~min}$ at room temperature. The membranes were washed with TBS with $20 \%$ Tween-3 times and peroxidase activity was detected on X-ray films using an enhanced chemiluminescence detection system (Cell Signaling Technology, Inc.). The band intensities were measured by densitometry using Quantity One software v4.6.9 (Bio-Rad Laboratories, Inc., Hercules, CA, USA). The size of the FXYD3 band was consistent with the predicted molecular weight of the FXYD3 protein and was normalized to GAPDH protein levels.

$I H C$. Paraffin-embedded tissue sections, $4-\mu \mathrm{m}$ thick, were cut and mounted on glass slides. The samples were subsequently deparaffinized in dimethylbenzene and rehydrated using 100 , 95, 90, 80 and $70 \%$ ethanol solutions. Endogenous peroxidase activity was blocked using $0.3 \%$ hydrogen peroxide at room temperature for $10 \mathrm{~min}$. For antigen retrieval, the slides were boiled in citrate-hydrochloric acid (pH 6.0) (cat. no. ZLI-9065; OriGene Technologies, Inc.) for $20 \mathrm{~min}$ in a pressure cooker. Subsequent to washing in PBS, the slides were treated with 5\% sheep serum albumin (cat. no. ab7481; Abcam) at room temperature for $15 \mathrm{~min}$ to prevent non-specific binding. The tissue sections were then incubated with rabbit anti-FXYD3 (cat. no. ab205534; dilution 1:400; Abcam) overnight at $4^{\circ} \mathrm{C}$. Following the primary antibody incubation, the tissue sections were incubated with an HRP-conjugated secondary antibody (Dako; Agilent Technologies, Inc., Santa Clara, CA, USA) for 
Table I. Clinicopathological data of patients with hepatocellular carcinoma.

\begin{tabular}{|c|c|c|c|c|}
\hline \multirow[b]{2}{*}{ Variables } & \multirow[b]{2}{*}{ Cases, $\mathrm{n}$} & \multicolumn{2}{|c|}{ FXYD3 protein expression } & \multirow[b]{2}{*}{ P-value } \\
\hline & & Low, n (\%) & High, n (\%) & \\
\hline \multicolumn{5}{|l|}{ Age, years } \\
\hline$\leq 50$ & 70 & $43(61.4)$ & $27(38.6)$ & \multirow[t]{2}{*}{0.231} \\
\hline$>50$ & 67 & $34(50.7)$ & $33(49.3)$ & \\
\hline \multicolumn{5}{|l|}{ Sex } \\
\hline Male & 124 & $69(55.6)$ & $55(44.4)$ & \multirow[t]{2}{*}{0.775} \\
\hline Female & 13 & $8(61.5)$ & $5(38.5)$ & \\
\hline \multicolumn{5}{|c|}{ Hepatitis B surface antigen } \\
\hline Negative & 69 & $39(56.5)$ & $30(43.5)$ & \multirow[t]{2}{*}{0.604} \\
\hline Positive & 68 & $38(55.9)$ & $30(44.1)$ & \\
\hline \multicolumn{5}{|c|}{ Serum AFP, $\mu \mathrm{g} / \mathrm{ml}$} \\
\hline$\leq 400$ & 86 & $47(54.7)$ & $39(45.3)$ & \multirow[t]{2}{*}{0.722} \\
\hline$>400$ & 51 & $30(58.8)$ & $21(41.2)$ & \\
\hline \multicolumn{5}{|c|}{ Tumor size, $\mathrm{cm}$} \\
\hline$\leq 5$ & 60 & $37(61.7)$ & $23(38.3)$ & \multirow[t]{2}{*}{0.299} \\
\hline$>5$ & 77 & $40(51.9)$ & $37(48.1)$ & \\
\hline \multicolumn{5}{|l|}{ Tumor no. } \\
\hline Single & 100 & $63(63.0)$ & $37(37.0)$ & \multirow[t]{2}{*}{$0.011^{\mathrm{b}}$} \\
\hline Multiple & 37 & $14(37.8)$ & $23(62.2)$ & \\
\hline \multicolumn{5}{|c|}{ Microvascular invasion } \\
\hline No & 123 & $66(53.7)$ & $57(46.3)$ & \multirow[t]{2}{*}{0.092} \\
\hline Yes & 14 & $11(78.6)$ & $3(21.4)$ & \\
\hline \multicolumn{5}{|c|}{ Liver cirrhosis } \\
\hline No & 90 & $48(53.9)$ & $41(46.1)$ & \multirow[t]{2}{*}{0.591} \\
\hline Yes & 47 & $28(59.6)$ & $19(40.4)$ & \\
\hline \multicolumn{5}{|c|}{ Differentiation grade } \\
\hline I+II & 74 & $41(55.4)$ & $33(44.6)$ & \multirow[t]{2}{*}{0.864} \\
\hline III+IV & 63 & $36(57.1)$ & $27(42.9)$ & \\
\hline \multicolumn{5}{|l|}{ TNM stage } \\
\hline I & 88 & $55(62.5)$ & $33(37.5)$ & \multirow[t]{2}{*}{0.051} \\
\hline II+III+IV & 49 & $22(44.9)$ & $27(55.1)$ & \\
\hline
\end{tabular}

AFP, $\alpha$ fetoprotein; TNM, tumor-node-metastasis; FYXD3, FXYD domain-containing ion transport regulator $3 .{ }^{\mathrm{a}} \chi^{2}$ test. ${ }^{\mathrm{b}} \mathrm{P}<0.05$.

$30 \mathrm{~min}$ at room temperature. The slides were then incubated with 3,3'-diaminobenzidine tetrahydrochloride for $10 \mathrm{~min}$ at room temperature, all sections were counterstained with hematoxylin for $\sim 2 \mathrm{~min}$ at room temperature. For the negative control, the primary antibody was replaced with rabbit IgG (cat. no. 3900; dilution 1:400; Cell Signaling Technology, Inc.) (data not shown). A positive control was provided by breast cancer tissue samples. The semi-quantitative FXYD3 expression score was calculated as the sum of the score for the proportion of positively stained tumor cells and the score for staining intensity. These scores were determined by two pathologists blinded to the clinical characteristics of the patients. The proportions of positively stained tumor cells were scored as follows: $0,<5 \%$ (negative); 1, 5-25\% (sporadic); 2, 25-50\% (focal); and 3, >50\% (diffuse). Staining intensity was graded according to the following scale: 0 , no staining; 1 , weak staining (light yellow);
2, moderate staining (yellow-brown); and 3, strong staining (brown). The total immunostaining score was calculated by multiplying the proportion of positively stained cells by the staining intensity score, yielding a value ranging from 0-9.

Statistical analysis. Statistical analysis was performed using SPSS 20.0 software (IBM Corp., Armonk, NY, USA). Scatterplots and bar graphs were created using GraphPad Prism version 6.0 (GraphPad Software, Inc., La Jolla, CA, USA). The distributions of the baseline characteristics of the two groups, which were separated according to a cutoff FXYD3 level of 1.285, were compared using $\chi^{2}$ or Fisher's exact tests. The Kaplan-Meier method and log-rank test were used to plot survival curves and to calculate the difference in survival between the groups. Parameters found to be significant by univariate analysis were further evaluated by multivariate 

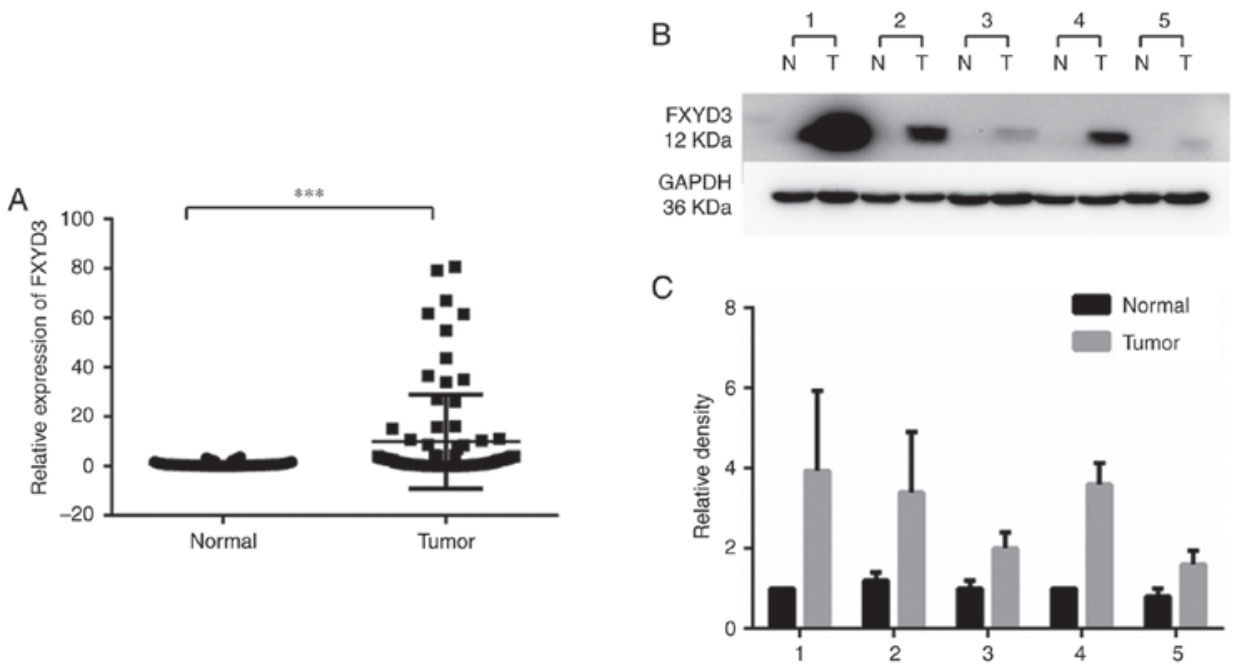

Figure 1. Overexpression of FXYD3 in HCC. (A) Relative expression levels of FXYD3 were detected by reverse transcription-quantitative polymerase chain reaction in 80 pairs of HCC and non-cancerous normal liver tissue. In the scatterplot, each dot represents one tissue sample. The expression of FXYD3 was significantly higher in HCC compared with the non-cancerous liver tissue. (B) At the protein level, 5 pairs of samples (20.8\%) showed significant expression upon western blotting. This image is representative of 3 replicates. (C) Quantification revealed that the expression of FXYD3 was significantly higher in HCC than in non-cancerous tissue. ${ }^{* * *} \mathrm{P}<0.001$ vs. normal. HCC, hepatocellular carcinoma; T, HCC; N, non-cancerous liver tissue; FYXD3, FXYD domain-containing ion transport regulator 3 .

A

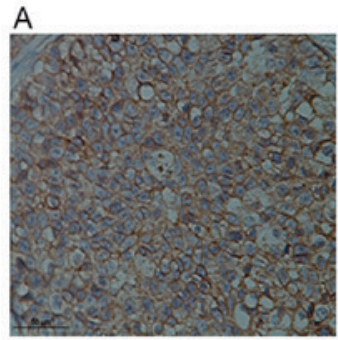

E

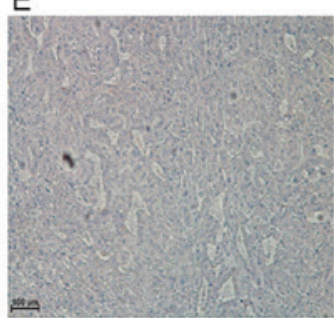

B

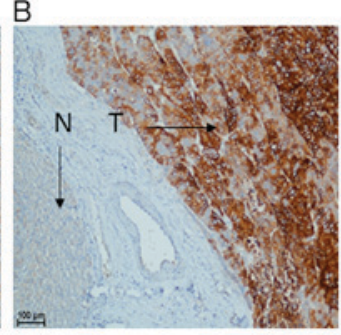

F

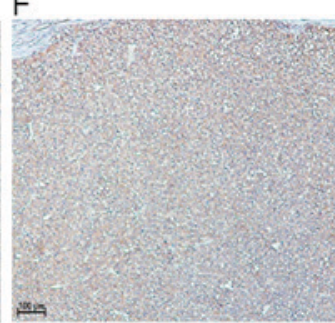

C

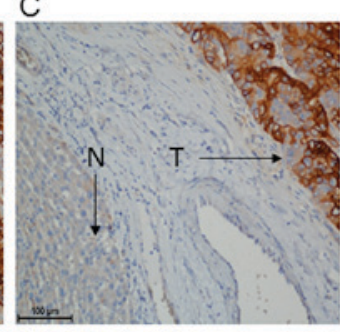

G

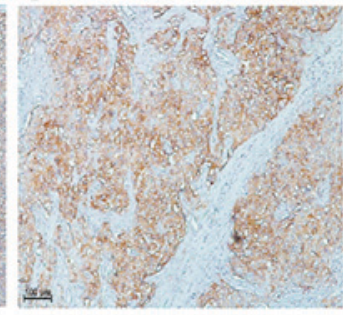

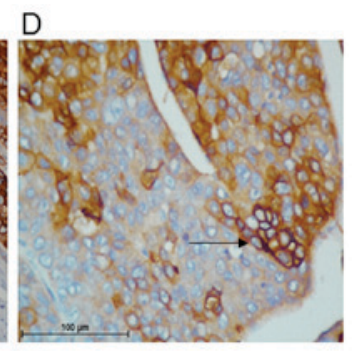

$\mathrm{H}$

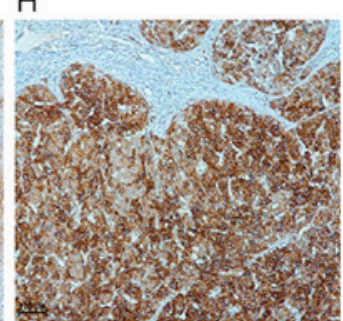

Figure 2. Immunohistochemical staining of FXYD3 in HCC tissue compared with adjacent non-cancerous tissue. (A) Positive control of breast cancer tissue samples at magnification, $\mathrm{x} 400$; the arrows indicate FXYD3 protein expression in HCC and matched normal liver tissues. Representative images (B) at magnification, x100; (C) x200; and (D) x400 demonstrating FXYD3 expression localized in the cell membrane. (E) Negative staining of FXYD3 (magnification, x100). (F) Weak positive staining of FXYD3 (magnification, x100). (G) Moderate positive staining of FXYD3 (magnification, x100). (H) Strong positive staining of FXYD3 (magnification, x100). HCC, hepatocellular carcinoma; FYXD3, FXYD domain-containing ion transport regulator 3.

Cox regression analysis. $\mathrm{P}<0.05$ was considered to indicate a statistically significant difference.

\section{Results}

Patients and clinicopathological data. The expression of FXYD3 was analyzed in each tissue sample at the mRNA and protein levels. FXYD3 expression in the 80 pairs of HCC tissues and matched non-cancerous liver tissues was analyzed by RT-qPCR, and 24 pairs were also evaluated by western blotting. Furthermore, 137 paraffin-embedded primary HCC tumor samples were analyzed by IHC analysis. The associations between patient clinicopathological data and
FXYD3 expression levels in patients with HCC are summarized in Table I. $\chi^{2}$ tests demonstrated that FXYD3 expression levels were significantly different between patients with one vs. multiple tumors $(\mathrm{P}=0.011)$.

FXYD3 overexpression in HCC. RT-qPCR and western blotting were performed to analyze the expression of FXYD3 in HCC and non-cancerous liver tissue samples. This revealed that FXYD3 expression was significantly elevated in the HCC tissues compared with non-tumor tissues at the mRNA and protein levels (Fig. 1). Fig. 1B is a representative image of 3 replicates. The western blots of 5 paired samples $(20.8 \%)$ showed significant protein expression and the remaining 
Table II. Prognostic significance of FXYD3 protein in hepatocellular carcinoma patients.

\begin{tabular}{|c|c|c|c|c|c|c|}
\hline \multirow[b]{2}{*}{ Variables } & \multicolumn{3}{|c|}{ Univariate analysis } & \multicolumn{3}{|c|}{ Multivariate analysis } \\
\hline & HR & $95 \% \mathrm{CI}$ & P-value & HR & $95 \% \mathrm{CI}$ & P-value \\
\hline FXYD3 & 2.643 & $1.524-4.582$ & $0.001^{\mathrm{a}}$ & 2.137 & $1.224-3.732$ & $0.008^{\mathrm{a}}$ \\
\hline Age (years) & 1.146 & $0.673-1.952$ & 0.615 & & & \\
\hline Sex & 1.127 & $0.483-2.632$ & 0.782 & & & \\
\hline Hepatitis B surface antigen & 1.013 & $0.434-2.368$ & 0.976 & & & \\
\hline Serum AFP & 1.397 & $0.814-2.397$ & 0.226 & & & \\
\hline Tumor size & 2.232 & $1.246-3.998$ & $0.007^{\mathrm{a}}$ & 1.935 & $1.076-3.480$ & $0.027^{\mathrm{a}}$ \\
\hline Tumor number & 5.077 & $2.968-8.683$ & $<0.001^{\mathrm{a}}$ & 4.131 & $2.401-7.109$ & $<0.001^{\mathrm{a}}$ \\
\hline Microvascular invasion & 1.996 & $0.901-4.425$ & 0.089 & & & \\
\hline Liver cirrhosis & 1.311 & $0.761-2.260$ & 0.330 & & & \\
\hline Differentiation grade & 1.222 & $1.720-2.074$ & 0.457 & & & \\
\hline TNM stage & 4.535 & $2.619-7.855$ & $<0.001^{\mathrm{a}}$ & & & 0.237 \\
\hline
\end{tabular}

AFP, $\alpha$ fetoprotein; TNM, tumor-node-metastasis; CI, confidence interval; FYXD3, FXYD domain-containing ion transport regulator 3. ${ }^{2} \mathrm{P}<0.05$.

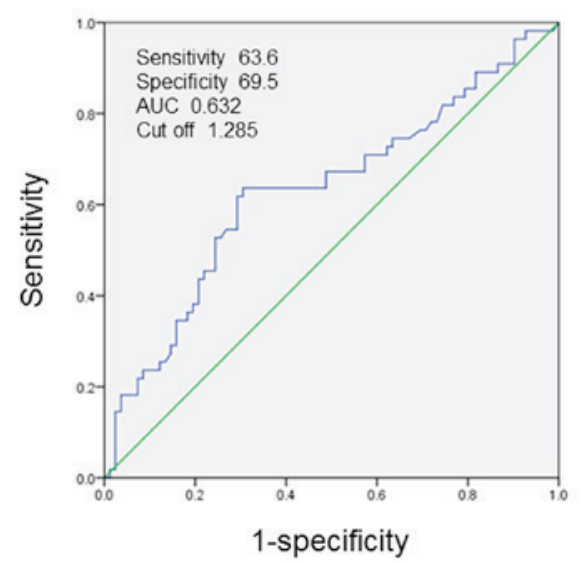

B

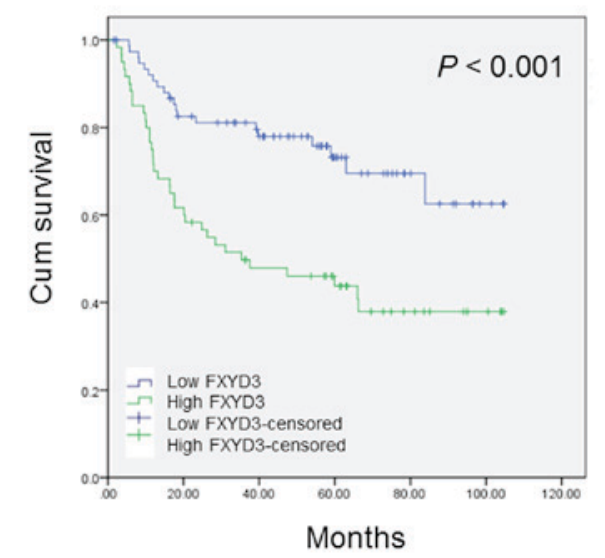

Figure 3. Prognostic significance of FXYD3 protein in patients with HCC patients. (A) FXYD3 protein expression interpreted by receiver operating characteristic curve analysis. (B) Survival curve regarding the association between FXYD3 expression and OS rate of HCC patients. Kaplan-Meier analysis of the OS rate of HCC patients with varying expression levels of FXYD3. Patients exhibiting high expression of FXYD3 demonstrated a worse overall survival rate compared with those exhibiting low expression of FXYD3. HCC, hepatocellular carcinoma; OS, overall survival; AUC, area under curve; FYXD3, FXYD domain-containing ion transport regulator 3.

samples $(79.2 \%)$ did not exhibit visible expression. IHC analysis of 137 HCC tissues was used to assess the function and prognostic significance of FXYD3 in HCC. Positive staining for FXYD3 was indicated by the presence of brown granules in the cell membrane and cytoplasm. The specimens were divided into a high FXYD3 expression group (n=60; 43.8\%) and a low FXYD3 expression group $(n=77 ; 56.2 \%)$, which exhibited staining ranging from strongly and moderately positive to weakly positive and negative, respectively (Fig. 2).

Prognostic significance of FXYD3 protein expression in HCC patients. Receiver operating characteristic (ROC) curve analysis was performed to determine the cutoff score for FXYD3 protein expression. The score closest to the point at which maximum sensitivity and specificity were displayed was selected as the cutoff score. The area under the ROC curve was calculated to estimate the power of FXYD3 to predict the
OS rate over the entire range of scores. According to the ROC curve analysis results (Fig. 3A), the cohort was classified into a high expression group and a low expression group to evaluate the prognostic value of the FXYD3 in HCC patients.

The IHC results were used to evaluate the association between HCC clinicopathological parameters and FXYD3 expression. The cutoff score (1.285) generated by ROC curve analysis, was used for classification by high and low FXYD3 expression. Kaplan-Meier analysis and the log-rank test were performed to analyze the association between FXYD3 protein expression and OS. OS time was significantly higher in the group with low FXYD3 expression levels than in the group with high FXYD3 expression levels ( $\mathrm{P}<0.001$; Fig. 3B).

Univariate Cox regression analysis demonstrated that FXYD3 expression $(\mathrm{P}=0.001)$, tumor size $(\mathrm{P}=0.007)$, tumor number $(\mathrm{P}<0.001)$ and tumor stage $(\mathrm{TNM})(\mathrm{P}<0.001)$ were significant risk factors for OS (Table II). Multivariate 
Cox regression analysis indicated that FXYD3 expression $(\mathrm{P}=0.008)$, tumor size $(\mathrm{P}=0.027)$, and tumor number $(\mathrm{P}<0.001)$ were independent prognostic factors in patients with HCC (Table II).

\section{Discussion}

The predominant clinical staging system for liver cancer is the Barcelona Clinic Liver Cancer system, which is useful for predicting prognoses and stratifying patients for treatment (23). A series of predictive biomarkers, including meprin A subunit $\alpha$, vascular endothelial growth factor and insulin-like growth factor-1, have facilitated improvements in the OS and prognosis for patients with HCC in the early and advanced stages of the disease when used in combination with the aforementioned staging system (24-26). The identification of additional novel predictive markers may significantly improve patient clinical outcomes.

A series of studies have reported that FXYD3 is expressed in numerous types of cancer. FXYD3 expression was initially described in breast cancer (7), and subsequently detected in prostate cancer, CRC, pancreatic cancer and ESCC, in which FXYD3 was reported to be significantly upregulated in tumor tissues compared with normal adjacent mucosal tissues (11-17). However, in lung cancer and glioma, FXYD3 was demonstrated to be expressed at low levels compared with healthy paracancerous tissues (18-20). FXYD3 was originally identified in murine mammary tumors. Morrison and Leder (6) determined that FXYD3 expression was induced by the Neu and Ras genes rather than the c-Myc and Int-2 genes. In human mammary epithelial cells, transforming growth factor- $\beta$ has been demonstrated to cause downregulation of FXYD3 expression through the zinc finger E-box binding homeobox 1 pathway (27,28). In CRC, FXYD3 expression is hypothesized to be associated with p53 expression, as the FXYD3 promoter contains the p53 binding site. Increased CRC cell apoptosis, despite p53 mutations, has been demonstrated to be associated with small interfering FXYD3 (29,30). However, there is little knowledge regarding the association between FXYD3 expression and the clinical prognosis of HCC patients.

The $\mathrm{Na}^{+}-\mathrm{K}^{+}$ATPase is composed of tetramers of $\alpha$ and $\beta$ subunits and is located in the plasma membrane. The channel transports three $\mathrm{Na}^{+}$ions out of the cell and two $\mathrm{K}^{+}$ions into the cell to maintain cellular homeostasis (31). The $\mathrm{Na}^{+}-\mathrm{K}^{+}$ATPase has been demonstrated to be associated with cancer initiation, growth, development and metastasis (32). It has also been demonstrated to function in the $\mathrm{p} 38$ mitogen-activated protein kinase/extracellular signal-regulated kinase signaling cascade, Src kinase activity, phosphoinositide 3-kinase/Akt/mechanistic target of rapamycin signaling and the epithelial-mesenchymal transition, all of which are important pathways in tumorigenesis and tumor progression (32). Furthermore, it has been reported that cardiac steroids (cardiac glycosides), which are potent $\mathrm{Na}^{+}-\mathrm{K}^{+}$pump inhibitors, can postpone tumor recurrence and metastasis, prolong survival times and increase survival rates of post-surgical patients with HCC (33-36). FXYD3 can function as a $\beta$-subunit of the $\mathrm{Na}^{+}-\mathrm{K}^{+}$ATPase and modulate certain cell functions. However, FXYD3 can also affect glycosylation of the $\beta$-subunit of $X$, K-ATPase when co-expressed in Xenopus oocytes (33-35). Glycosylation is closely associated with tumorigenesis $(36,37)$; however, whether FXYD3-mediated glycosylation of $\mathrm{Na}^{+}-\mathrm{K}^{+}$ATPase contributes to HCC growth, invasion and/or metastasis requires investigation in future studies.

FXYD3 expression was examined at the transcriptional and translational levels by RT-qPCR, western blotting and IHC. Using RT-qPCR, it was demonstrated that FXYD3 expression was significantly elevated in HCC tumor tissues compared with that in non-cancerous liver tissues. These results were supported by those achieved through western blotting. It is important to note that microvascular invasion is a key determinant of prognosis in patients with HCC. However, the present study indicated no significant association between FXYD3 expression and microvascular invasion using $\chi^{2}$ analysis. ROC curve analysis was performed to identify a cutoff value with which to classify patients into high or low FXYD3 expression groups. Using Kaplan-Meier analysis and the log-rank test, it was determined that FXYD3 expression is associated with OS at the protein level $(\mathrm{P}<0.001)$ and that high FXYD3 expression was predictive of a poor prognosis in patients with HCC. Univariate and multivariate Cox regression analyses indicated that FXYD3 protein expression level was an independent prognostic factor $(\mathrm{P}=0.008)$ in patients with HCC. However, it is possible that bias may have resulted in group-group differences in survival.

In conclusion, elevated FXYD3 mRNA and protein expression levels are predictive of poor survival. The present study partially clarifies the role of FXYD3 in HCC, however, the precise mechanism underlying the association between the expression of FXYD3 and HCC remains to be elucidated. Further large multicenter studies are required to achieve this.

\section{Acknowledgements}

This study was supported by the National Natural Science Foundation of China (grant nos. 81625017 and 81572385) and the Fundamental Research Funds for the Central Universities of China (grant no. 16ykjc36).

\section{References}

1. Forner A, Llovet JM and Bruix J: Hepatocellular carcinoma. Lancet 379: 1245-1255, 2012.

2. He G, Dhar D, Nakagawa H, Font-Burgada J, Ogata H, Jiang Y, Shalapour S, Seki E, Yost SE, Jepsen K, et al: Identification of liver cancer progenitors whose malignant progression depends on autocrine IL-6 signaling. Cell 155: 384-396, 2013.

3. Li Z, Tuteja G, Schug J and Kaestner KH: Foxa1 and Foxa2 are essential for sexual dimorphism in liver cancer. Cell 148: 72-83, 2012.

4. Torre LA, Bray F, Siegel RL, Ferlay J,Lortet-Tieulent J and Jemal A: Global cancer statistics, 2012. CA Cancer J Clin 65: 87-108, 2015.

5. Maluccio $\mathrm{M}$ and Covey A: Recent progress in understanding, diagnosing, and treating hepatocellular carcinoma. CA Cancer J Clin 62: 394-399, 2012.

6. Morrison BW and Leder P: Neu and ras initiate murine mammary tumors that share genetic markers generally absent in c-myc and int-2-initiated tumors. Oncogene 9: 3417-3426, 1994.

7. Morrison BW, Moorman JR, Kowdley GC, Kobayashi YM, Jones LR and Leder P: Mat-8, a novel phospholemman-like protein expressed in human breast tumors, induces a chloride conductance in Xenopus oocytes. J Biol Chem 270: 2176-2182, 1995.

8. Zhuang L, Xu L, Wang P, Jiang Y, Yong P, Zhang C, Zhang H, Meng $\mathrm{Z}$ and Yang P: $\mathrm{Na}^{+} / \mathrm{K}^{+}$-ATPase $\alpha 1$ subunit, a novel therapeutic target for hepatocellular carcinoma. Oncotarget 6: 28183-28193, 2015. 
9. Capendeguy $\mathrm{O}$ and Horisberger JD: Functional effects of $\mathrm{Na}^{+}, \mathrm{K}^{+}$-ATPase gene mutations linked to familial hemiplegic migraine. Neuromolecular Med 6: 105-116, 2004.

10. Capurro C, Coutry N, Bonvalet JP, Escoubet B, Garty H and Farman N: Cellular localization and regulation of CHIF in kidney and colon. Am J Physiol 271: C753-C762, 1996.

11. Vaarala MH, Porvari K, Kyllönen A and Vihko P: Differentially expressed genes in two LNCaP prostate cancer cell lines reflecting changes during prostate cancer progression. Lab Invest 80: 1259-1268, 2000.

12. Grzmil M, Voigt S, Thelen P, Hemmerlein B, Helmke K and Burfeind P: Up-regulated expression of the MAT- 8 gene in prostate cancer and its siRNA-mediated inhibition of expression induces a decrease in proliferation of human prostate carcinoma cells. Int J Oncol 24: 97-105, 2004.

13. Widegren E, Onnesjö S, Arbman G, Kayed H, Zentgraf H, Kleeff J, Zhang H and Sun XF: Expression of FXYD3 protein in relation to biological and clinicopathological variables in colorectal cancers. Chemotherapy 55: 407-413, 2009.

14. Iacobuzio-Donahue CA, Maitra A, Olsen M, Lowe AW, van Heek NT, Rosty C, Walter K, Sato N, Parker A, Ashfaq R, et al: Exploration of global gene expression patterns in pancreatic adenocarcinoma using cDNA microarrays. Am J Pathol 162 1151-1162, 2003

15. Friess H, Ding J, Kleeff J, Fenkell L, Rosinski JA, Guweidhi A, Reidhaar-Olson JF, Korc M, Hammer J and Büchler MW: Microarray-based identification of differentially expressed growth- and metastasis-associated genes in pancreatic cancer. Cell Mol Life Sci 60: 1180-1199, 2003.

16. Logsdon CD, Simeone DM, Binkley C, Arumugam T, Greenson JK, Giordano TJ, Misek DE, Kuick R and Hanash S: Molecular profiling of pancreatic adenocarcinoma and chronic pancreatitis identifies multiple genes differentially regulated in pancreatic cancer. Cancer Res 63: 2649-2657, 2003

17. Zhu ZL, Yan BY, Zhang Y, Yang YH, Wang MW, Zentgraf $H$, Zhang XH and Sun XF: Overexpression of FXYD-3 is involved in the tumorigenesis and development of esophageal squamous cell carcinoma. Dis Markers 35: 195-202, 2013.

18. Gordon GJ, Richards WG, Sugarbaker DJ, Jaklitsch MT and Bueno R: A prognostic test for adenocarcinoma of the lung from gene expression profiling data. Cancer Epidemiol Biomarkers Prev 12: 905-910, 2003.

19. Okudela K, Yazawa T, Ishii J, Woo T, Mitsui H, Bunai T, Sakaeda M, Shimoyamada H, Sato H, Tajiri M, et al: Down-regulation of FXYD3 expression in human lung cancers: Its mechanism and potential role in carcinogenesis. Am J Pathol 175: 2646-2656, 2009.

20. Wang MW, Gu P, Zhang ZY, Zhu ZL, Geng Y, Kayed H, Zentgraf $\mathrm{H}$ and Sun XF: FXYD3 expression in gliomas and its clinicopathological significance. Oncol Res 18: 133-139, 2009.

21. Livak KJ and Schmittgen TD: Analysis of relative gene expression data using real-time quantitative PCR and the 2(-Delta Delta C(T)) method. Methods 25: 402-408, 2001

22. Instructions of the Anti-FXYD3 antibody: Anti-FXYD3 antibody [EPR17160] ab205534. http://www.abcam.com/fxyd3-anti body-epr17160-ab205534.html.

23. Llovet JM, Brú C and Bruix J: Prognosis of hepatocellular carcinoma: The BCLC staging classification. Semin Liver Dis 19 329-338, 1999.

24. OuYang HY, Xu J, Luo J, Zou RH, Chen K, Le Y, Zhang YF, Wei W, Guo RP and Shi M: MEP1A contributes to tumor progression and predicts poor clinical outcome in human hepatocellular carcinoma. Hepatology 63: 1227-1239, 2016.
25. Kaseb AO, Hassan MM, Lin E, Xiao L, Kumar V, Pathak P, Lozano R, Rashid A, Abbruzzese JL and Morris JS: V-CLIP: Integrating plasma vascular endothelial growth factor into a new scoring system to stratify patients with advanced hepatocellular carcinoma for clinical trials. Cancer 117: 2478-2488, 2011.

26. Kaseb AO, Abbruzzese JL, Vauthey JN, Aloia TA, Abdalla EK, Hassan MM, Lin E, Xiao L, El-Deeb AS, Rashid A and Morris JS: I-CLIP: Improved stratification of advanced hepatocellular carcinoma patients by integrating plasma IGF-1 into CLIP score. Oncology 80: 373-381, 2011.

27. Yamamoto H, Mukaisho K, Sugihara H, Hattori T and Asano S: Down-regulation of FXYD3 is induced by transforming growth

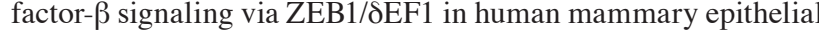
cells. Biol Pharm Bull 34: 324-329, 2011.

28. Herrmann P and Aronica SM: Estrogen and tamoxifen up-regulate FXYD3 on breast cancer cells: Assessing the differential roles of ER $\alpha$ and ZEB1. SpringerPlus 4: 245, 2015.

29. Bibert S, Aebischer D, Desgranges F, Roy S, Schaer D, Kharoubi-Hess S, Horisberger JD and Geering K: A link between FXYD3 (Mat-8)-mediated Na,K-ATPase regulation and differentiation of Caco-2 intestinal epithelial cells. Mol Biol Cell 20: 1132-1140, 2009.

30. Maxwell PJ, Longley DB, Latif T, Boyer J, Allen W, Lynch M, McDermott U, Harkin DP, Allegra CJ and Johnston PG: Identification of 5-fluorouracil-inducible target genes using cDNA microarray profiling. Cancer Res 63: 4602-4606, 2003.

31. Kanai R, Ogawa H, Vilsen B, Cornelius F and Toyoshima C: Crystal structure of a $\mathrm{Na}^{+}$-bound $\mathrm{Na}^{+}, \mathrm{K}^{+}$-ATPase preceding the E1P state. Nature 502: 201-206, 2013.

32. Durlacher CT, Chow K, Chen XW, He ZX, Zhang X, Yang T and Zhou SF: Targeting $\mathrm{Na}^{+} / \mathrm{K}^{+}$-translocating adenosine triphosphatase in cancer treatment. Clin Exp Pharmacol Physiol 42: 427-443, 2015

33. Crambert G, Li C, Claeys D and Geering K: FXYD3 (Mat-8), a new regulator of $\mathrm{Na}$, K-ATPase. Mol Biol Cell 16: 2363-2371, 2005.

34. Yue Q, Zhen H, Huang M, Zheng X, Feng L, Jiang B, Yang M, Wu W, Liu X and Guo D: Proteasome inhibition contributed to the cytotoxicity of arenobufagin after its binding with $\mathrm{Na}$, K-ATPase in human cervical carcinoma HeLa cells. PLoS One 11: e0159034, 2016.

35. Chen Z, Chen HY, Lang QB, Li B, Zhai XF, Guo YY, Yue XQ and Ling CQ: Preventive effects of jiedu granules combined with cinobufacini injection versus transcatheter arterial chemoembolization in post-surgical patients with hepatocellular carcinoma: A case-control trial. Chin J Integr Med 18: 339-344, 2012.

36. Hart GW and Copeland RJ: Glycomics hits the big time. Cell 143: 672-676, 2010.

37. Dalziel M, Crispin M, Scanlan CN, Zitzmann N and Dwek RA: Emerging principles for the therapeutic exploitation of glycosylation. Science 343: 1235681, 2014.

This work is licensed under a Creative Commons Attribution-NonCommercial-NoDerivatives 4.0 International (CC BY-NC-ND 4.0) License. 